\title{
Intrathecal Baclofen Dosage for Long-Term Treatment of Patients With Spasticity Due to Traumatic Spinal Cord Injuries or Multiple Sclerosis
}

\author{
Bengt Skoog, MD, PhD ${ }^{1}$, Bjo̊rn Hedman, $\mathrm{MD}^{2}$
}

\begin{abstract}
${ }^{1}$ Department of Clinical Neuroscience, Institute of Neuroscience and Physiology, The Sahlgrenska Academy, University of Gothenburg, Gothenburg; ${ }^{2}$ Department of Neurology, Karolinska Hospital, Stockholm, Sweden
\end{abstract}

Objective To investigate dosage changes in intrathecal baclofen during long-term treatment of patients with severe leg spasticity.

Methods We performed a retrospective chart review of 49 patients treated with an intrathecal baclofen pump (ITB) because of severe leg spasticity, for a minimum of 7 years. Eight patients were excluded due to catheter/pump failure or factors aggravating spasticity. Of the remaining 41 patients, 19 had spinal cord injury (SCI) and 22 were diagnosed with multiple sclerosis (MS). Among the SCI patients, 15 had cervical and 4 thoracic SCI, with 7 patients showing the American Spinal Injury Association impairment scale (AIS) A and 12 patients with AIS B-D. The dose was regulated by discussion among the patients and their physicians, usually 4-10 times annually, to reduce leg spasticity and also avoid leg/trunk weakness.

Results After 1 year patients on ITB needed a median dose of $168 \mu \mathrm{g} / 24 \mathrm{hr}$ (range, 30-725 $\mu \mathrm{g}$ ) for an optimal effect. After 7 to 10 years the dosage needed to reduce leg spasticity in the MS patients was significantly increased compared with the initial dose (mean $157 \%, \mathrm{n}=22$ and mean $194 \%, \mathrm{n}=18$ ). In contrast, the SCI patients needed only a modest increase (mean $113 \%$ and $121 \%$ ). The difference between MS and SCI patients was significant ( $t$-test $\mathrm{p}=0.006$ and $\mathrm{p}=0.004)$.

Conclusion The increased dosage in MS patients compared with patients diagnosed with SCI probably reflects the progressive disease course. The need for a large dosage increase in patients with SCI suggests possible pump failure, triggering factors for spasticity or progressive spinal disease.

Keywords Muscle spasticity, Spinal infusion, Baclofen, Spinal cord injuries, Multiple sclerosis 


\section{INTRODUCTION}

Involuntary motor activity often follows lesions of motor pathways in the central nervous system. Traditionally spasticity has been assessed by the clinical signs [1]. However a large percentage of patients report involuntary motor activity without the sign of spasticity $[2,3]$. The definition of spasticity has therefore been suggested to include all involuntary muscle activity following an upper motor neuron lesion [4]. Spasticity is considered problematic if it is perceived by the individual or caregivers "as hindering body function, activities and/or participation" [5].

Spasticity affects a majority of persons with spinal cord injuries (SCI) $[2,6]$, develops during the first months after the injury and persists over a long time after the injury. Intrathecal baclofen administration (ITB) is an effective and safe treatment for severe leg spasticity up to 9 years [7-10]. The dose usually stabilizes after 1-2 years. In contrast to SCI, multiple sclerosis (MS) is usually a progressive disease and the progressive stage invariably includes spastic paraparesis [11]. This spasticity also responds well to ITB $[7,12]$. Treatment exceeding 7 years improves the Ashworth Scale as well as the Barthel Index [13]. Tolerance to ITB after SCI was reported in up to $22 \%$ of patients within 3 years [14] while another study with a longer follow-up failed to show the need for increased dosage in patients with SCI and MS [15]. However, in the latter study the dose changes were estimated by complex statistics and involved a small number of patients with a longer follow-up.

The present study sought to investigate changes in ITB dosage after 7 years of treatment and beyond, and compared the dose evolution in patients with a stable neurological condition (SCI), and in patients with a progressive neurological condition (MS). Since dosages vary considerably between patients, the present study investigated the changes in each individual patient.

\section{MATERIALS AND METHODS}

A retrospective chart review was approved by the Regionala Etikprovningsnamnden i Goteborg, M2 (No. 37516). Patients were selected if they were treated with ITB over a period of at least 7 years for severe leg spasticity $(\mathrm{n}=49)$.

All the patients exhibited severe leg and occasional trunk spasticity and failed to respond effectively to oral baclofen, or showed severe side effects. Indications for ITB treatment include a significantly decreased score on the Ashworth Scale following an intrathecal test dose of baclofen. ITB was initiated in the first patient during 1989 and in the last patient 2008. Pump implantation followed standard procedures with a catheter tip positioned at the low thoracic level. The pump models used were Medtronic SynchroMed EL until 2002 followed by SynchroMed II. The pumps were usually replaced every 5 th or 7 th year, respectively.

The effect on spasticity was estimated by discussion among patients and their health providers including

Table 1. Patients omitted from follow-up due to pump system malfunction or other factors within 7 years after baclofen pump initiation

\begin{tabular}{cccccccc}
\hline Sex & Illness & $\begin{array}{c}\text { Age trauma/debut } \\
\text { MS (yr) }\end{array}$ & AIS/type MS & Level & $\begin{array}{c}\text { Pump start year after } \\
\text { trauma/debut }\end{array}$ & Problem & $\begin{array}{c}\text { Year after } \\
\text { pump start }\end{array}$ \\
\hline F & SCI & 17 & C & C6 & 2 & $\begin{array}{c}\text { Mental illness, } \\
\text { pressure sore }\end{array}$ & 7 \\
M & SCI & 41 & C & C4 & 3 & Pump infection & 7 \\
M & SCI & 18 & A & C4 & 16 & Pump & 7 \\
M & SCI & 20 & C & T7 & 8 & Catheter & 3 \\
M & MS & 20 & SPMS & - & 20 & Catheter & 5 \\
F & MS & 33 & SPMS & - & 19 & Catheter & 3 \\
F & MS & 19 & SPMS & - & 18 & Catheter & 3 \\
M & MS & 23 & SPMS & - & 16 & Catheter & 5 \\
\hline
\end{tabular}

MS, multiple sclerosis; AIS, American Spinal Injury Association impairment scale; SCI, spinal cord injury; SPMS, secondary progressive multiple sclerosis. 
nurse(s) and physician(s), usually 4-10 times per year, in order to reduce leg spasticity and avoid any increase in leg/trunk weakness. All the physicians were neurologists or experienced residents in neurology. They were all experienced in programming a baclofen pump. If the patient described spasticity during a particular time of the day, the pump was switched to flexdose and programmed to administer a higher dosage during this time. The medical records were reviewed for pump system failures or factors that aggravated spasticity. In the presence of any such problems, the follow-up of dosage changes was terminated 1 year before the event.

\section{Statistics}

The dosage one year after the start of ITB was compared with the dosage after 7 and 10 years in each patient. The mean percentage change in SCI patients was compared with that of the MS patients. The significance of the difference was tested by t-test. The t-test, Mann-Whitney Utest and univariate analysis of variance were calculated using SPSS version 22.0 (IBM, Armonk, NY, USA).

\section{RESULTS}

Of the 49 patients with a follow-up of 7 years or longer, eight presented with catheter/pump failure, which aggravated spasticity or mental problems within 7 years after starting pump treatment, which excluded them from the follow-up (Table 1). The most common factor was catheter failure and catheter tip dislodgement.

Table 2. Patients with multiple sclerosis

\begin{tabular}{|c|c|c|c|c|c|c|c|c|c|c|c|}
\hline Sex & $\begin{array}{c}\text { MS } \\
\text { debut } \\
\text { age (yr) }\end{array}$ & $\begin{array}{c}\text { Progress } \\
\text { (yr) }\end{array}$ & $\begin{array}{l}\text { Pump } \\
\text { disease } \\
(y \mathbf{y})\end{array}$ & $\begin{array}{c}\text { EDSS } \\
\text { pump } \\
\text { start }\end{array}$ & $\begin{array}{c}\text { Dose } \\
\text { year } 1\end{array}$ & $\begin{array}{c}\text { Dose } \\
\text { year } 7\end{array}$ & $\begin{array}{c}\% \\
\text { change } \\
\text { dose }\end{array}$ & $\begin{array}{c}\text { EDSS } \\
\text { year } \\
\text { seven }\end{array}$ & $\begin{array}{c}\text { Dose } \\
\text { pattern }\end{array}$ & $\begin{array}{l}\text { Reason for } \\
\text { change }\end{array}$ & $\begin{array}{c}\text { Pump } \\
\text { changed } \\
\text { year }\end{array}$ \\
\hline $\mathrm{F}$ & 44 & PP & 6 & 8.0 & 420 & 580 & 138 & 8.0 & Flex & Stiff evening & 8 \\
\hline $\mathrm{F}$ & 21 & 4 & 16 & 7.0 & 220 & 346 & 157 & 8.0 & Flex & Spasms & 8 \\
\hline $\mathrm{F}$ & 22 & 11 & 21 & 7.0 & 77 & 165 & 214 & 7.5 & Flex & Stiff at night & 5 \\
\hline $\mathrm{M}$ & 42 & PP & 30 & 8.0 & 120 & $300^{\mathrm{a})}$ & 250 & 9.5 & Cont & Stiffness & 7 \\
\hline $\mathrm{F}$ & 36 & 6 & 19 & 8.0 & 108 & 110 & 102 & 8.5 & Cont & Stiffness & $5,10,18$ \\
\hline $\mathrm{F}$ & 35 & PP & 16 & 9.0 & 130 & 330 & 254 & 9.5 & Cont & Stiffness & 8 \\
\hline $\mathrm{M}$ & 18 & 10 & 19 & 6.5 & 70 & 116 & 166 & 7.5 & Flex & Stiff at night & 6,16 \\
\hline $\mathrm{M}$ & 25 & SP & 31 & 7.0 & 78 & $121^{\text {a) }}$ & 155 & 7.5 & Cont & Spasticity & End year 7 \\
\hline $\mathrm{F}$ & 18 & SP & 36 & 9.0 & 80 & $91^{\text {a) }}$ & 114 & 9.0 & Cont & Spasticity & End year 7 \\
\hline $\mathrm{M}$ & 21 & 2 & 11 & 9.0 & 139 & 399 & 287 & 9.0 & Cont & Flexor spasm & 8 \\
\hline $\mathrm{F}$ & 28 & SP & 28 & 8.0 & 66 & $85^{\text {a) }}$ & 129 & 9.0 & Cont & Stiff morning & 7 \\
\hline $\mathrm{F}$ & 16 & SP & 29 & 7.0 & 89 & 170 & 191 & 8.0 & Flex & Spasms at night & 5,12 \\
\hline $\mathrm{F}$ & 29 & 9 & 30 & 7.0 & 94 & 105 & 112 & 9.0 & Cont & Stiffness & 8 \\
\hline $\mathrm{M}$ & 30 & SP & 19 & 7.5 & 259 & 400 & 154 & 8.0 & Flex & Spasms morning & 3,12 \\
\hline $\mathrm{M}$ & 30 & 3 & 16 & 8.0 & 385 & 473 & 123 & 9.0 & Cont & Rigidity & 8 \\
\hline $\mathrm{M}$ & 19 & 10 & 28 & 8.0 & 115 & 165 & 143 & 9.0 & Flex & Spasms & 5 \\
\hline $\mathrm{F}$ & 49 & PP & 2 & 8.0 & 77 & $88^{\text {a) }}$ & 114 & 9.0 & Cont & Spasticity & 7 \\
\hline $\mathrm{F}$ & 41 & SP & 14 & 8.0 & 100 & $120^{\text {a) }}$ & 120 & 8.5 & Cont & Spasticity & 7 \\
\hline $\mathrm{F}$ & 30 & SP & 27 & 8.0 & 200 & $180^{\mathrm{a})}$ & 90 & 8.0 & Cont & Spasticity & 7 \\
\hline $\mathrm{M}$ & 32 & PP & 19 & 8.5 & 190 & $200^{\mathrm{a})}$ & 105 & 9.0 & Cont & Spasticity & 7 \\
\hline $\mathrm{F}$ & 34 & SP & 26 & 8.5 & 375 & $250^{\mathrm{a})}$ & 67 & 9.5 & Cont & Spasticity & 7 \\
\hline $\mathrm{F}$ & 26 & SP & 15 & 8.0 & 90 & 250 & 278 & 9.0 & Cont & Spasticity & 5 \\
\hline
\end{tabular}

MS, multiple sclerosis; EDSS, Expanded Disability Status Scale; PP, primary progressive MS; SP, secondary progressive MS with unknown progression year; Flex, variable dose during 24 hours started within the first year; Cont, continuous dose (the same dose during 24 hours).

${ }^{\text {a) }}$ Dosage before the pump change. 
Of the remaining 41 patients, 19 had SCI and 22 MS. The 19 SCI patients included 15 cervical and 4 thoracic cases. The degree of spinal lesion was estimated by the American Spinal Cord Injury Association impairment score (AIS) - A ( $n=6), B(n=5), C(n=3)$, and D ( $n=3)$. The disability of patients with MS was estimated by the Expanded Disability Status Scale (EDSS) and ranged from 6.5 to 9.0 at the start of the pump treatment. After 7 years, the EDSS scores increased in 17 of the 21 MS patients (Table 2). In the last follow-up, all the MS patients except one showed severe disability (EDSS 8-9.5).

During the first year after implantation, the dosage was steadily increased to elicit a sustained effect on spasticity. Seven of the MS patients were treated with a dose that varied during the day or night (flex dose) and this regimen was introduced within the first year. The remainder of the patients were treated with the same dose throughout the day and night (continuous). One year after the start of ITB, the SCI patients (Table 3) needed a median daily dose of $260 \mu \mathrm{g} / 24 \mathrm{hr}$ (range, 30-725 $\mu \mathrm{g}$ ). The MS pa- tients (Table 2) required a lower dose, with a median dosage of $112 \mu \mathrm{g} / 24 \mathrm{hr}$ (range, $66-420 \mu \mathrm{g}$ ). The mean dosage for the SCI patients was $257 \mu \mathrm{g} / 24 \mathrm{hr}$ (95\% confidence interval [CI], 189-325) and for the MS patients $158 \mu \mathrm{g} / 24$ hr (95\% CI, 113-204), and the difference was significant ( $\mathrm{t}$-test $\mathrm{p}=0.02)$.

Seven and 10 years after initiating the pump treatment, the dosage was only slightly increased in the SCI group (Fig. 1), to median dosages $260 \mu \mathrm{g} / 24 \mathrm{hr}(\mathrm{n}=19)$ and 276 $\mu \mathrm{g} / 24 \mathrm{hr}(\mathrm{n}=19)$. In contrast, the dosage was considerably increased in the MS group, and the median dosages were $175 \mu \mathrm{g} / 24 \mathrm{hr}$ after 7 years $(\mathrm{n}=22)$, and $190 \mu \mathrm{g} / 24$ $\mathrm{hr}$ after 10 years $(\mathrm{n}=18)$. The dosage in each individual patient of the SCI group (Fig. 2) was increased to a mean of $113 \%$ (95\% CI, 99-128) after 7 years and to a mean of $121 \%$ (95\% CI, 104-139) after 10 years compared with the 1-year dosage (Fig. 3). By contrast, in the MS group the corresponding increases after 7 years were $158 \%$ (95\% CI, 131-184) and after 10 years $194 \%$ (95\% CI, 153-236). A ttest comparing the percentage change in the SCI and MS

Table 3. Patients with spinal cord injury

\begin{tabular}{|cccccccccccc}
\hline Sex & $\begin{array}{c}\text { Trauma } \\
\text { age (yr) }\end{array}$ & Level & AIS & Walker $\begin{array}{c}\text { Pump year } \\
\text { after trauma }\end{array}$ & $\begin{array}{c}\text { Dose } \\
\text { year } \mathbf{1}\end{array}$ & $\begin{array}{c}\text { Dose } \\
\text { year } \mathbf{7}\end{array}$ & $\begin{array}{c}\text { \% } \\
\text { change }\end{array}$ & $\begin{array}{c}\text { Dose } \\
\text { pattern }\end{array}$ & $\begin{array}{c}\text { Reason for } \\
\text { change }\end{array}$ & $\begin{array}{c}\text { Pump } \\
\text { changed } \\
\text { year }\end{array}$ \\
\hline M & 54 & C3 & A & No & 0.25 & 256 & $260^{\text {a) }}$ & 102 & Cont & Spasticity & 7 \\
\hline M & 18 & C4 & A & No & 1 & 264 & 360 & 136 & Cont & Spasticity & $4,10,15,22$ \\
\hline M & 28 & C4 & A & No & 6 & 260 & $300^{\text {a) }}$ & 115 & Cont & Spasticity & 7 \\
\hline F & 45 & C5 & A & No & 2 & 172 & 252 & 147 & Cont & Spasticity & 8 \\
M & 17 & C5 & A & No & 15 & 125 & 120 & 96 & Cont & Spasticity & 5,11 \\
\hline M & 20 & C5 & A & No & 4 & 168 & 330 & 196 & Cont & Spasticity & 5,11 \\
\hline M & 23 & C8 & A & No & 8 & 372 & 352 & 95 & Cont & Spasticity & 6,13 \\
\hline F & 41 & C7 & B & No & 9 & 360 & 336 & 93 & Cont & Spasticity & $5,10,15,22$ \\
\hline F & 47 & C7 & B & No & 1 & 167 & $168^{\text {a) }}$ & 101 & Cont & Spasticity & 7,12 \\
\hline F & 27 & C7 & B & No & 37 & 383 & $550^{\text {a) }}$ & 144 & Cont & Spasticity & 7,12 \\
\hline M & 48 & T4 & B & No & 2 & 264 & 240 & 91 & Cont & Spasticity & $5,10,17$ \\
\hline M & 23 & T7 & B & No & 8 & 276 & $253^{\text {a) }}$ & 92 & Cont & Spasticity & 7 \\
\hline M & 49 & C3 & C & Yes & 11 & 75 & 75 & 100 & Cont & Spasticity & 8 \\
\hline M & 59 & C4 & C & No & 0.25 & 725 & $750^{\text {a) }}$ & 103 & Cont & Spasticity & 7 \\
\hline M & 61 & C5 & C & No & 0.25 & 288 & 350 & 122 & Cont & Spasticity & 8 \\
\hline M & 26 & T11 & C & No & 1 & 361 & 396 & 110 & Cont & Spasticity & 5,13 \\
\hline M & 51 & C5 & D & Yes & 5 & 30 & 48 & 160 & Cont & Spasticity & $5,10,17$ \\
\hline M & 62 & C7 & D & Yes & 2 & 170 & $112^{\text {a) }}$ & 66 & Cont & Spasticity & 7 \\
\hline F & 56 & T1 & D & No & 4 & 168 & 143 & 85 & Cont & Spasticity & 8 \\
\hline A
\end{tabular}

AIS, American Spinal Injury Association impairment scale; Cont, continuous dose (the same dose during 24 hours).

${ }^{\text {a) }}$ Dose before the pump change. 
(A)

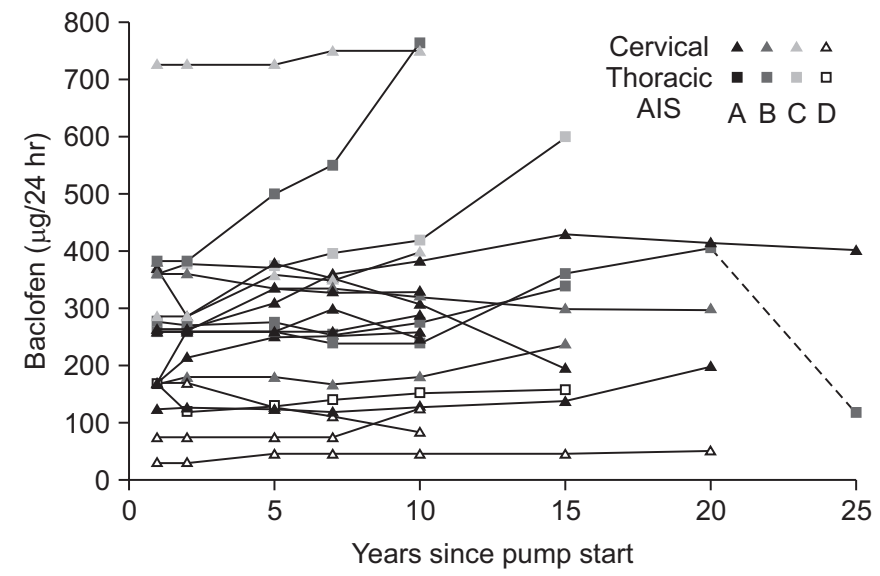

(B)

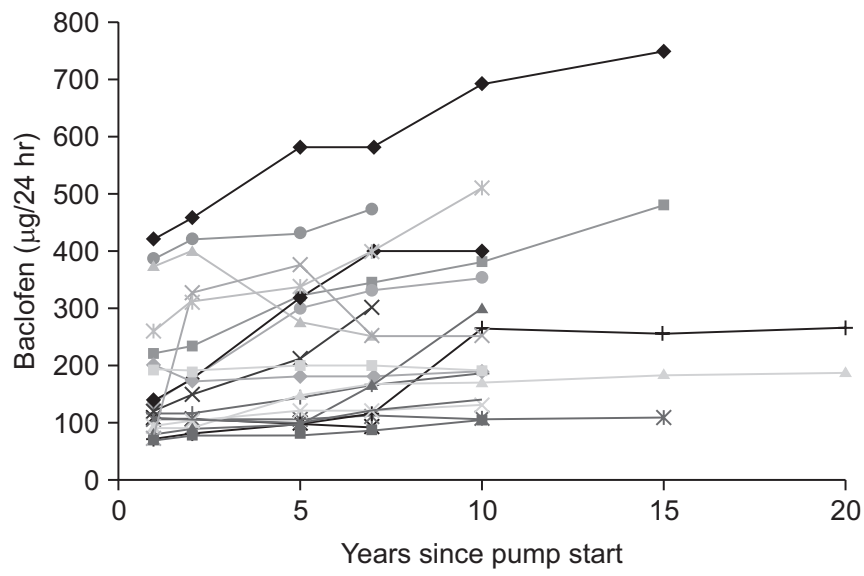

Fig. 1. Long-term changes in intrathecal baclofen dosage of patients with spinal cord injury (A) or multiple sclerosis (B). One patient with spinal cord injury had the pump system changed after 20 years (hatched line). AIS, American Spinal Cord Injury Association impairment score.

(A)

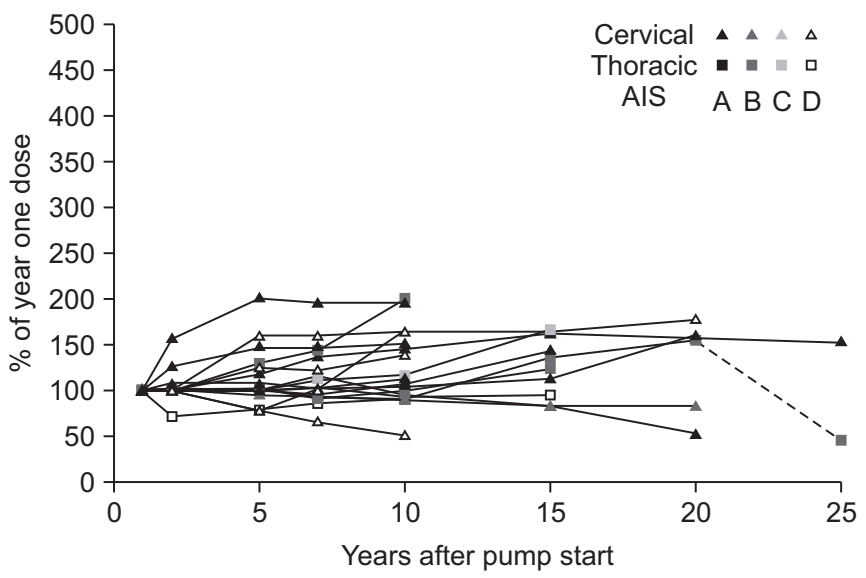

(B)

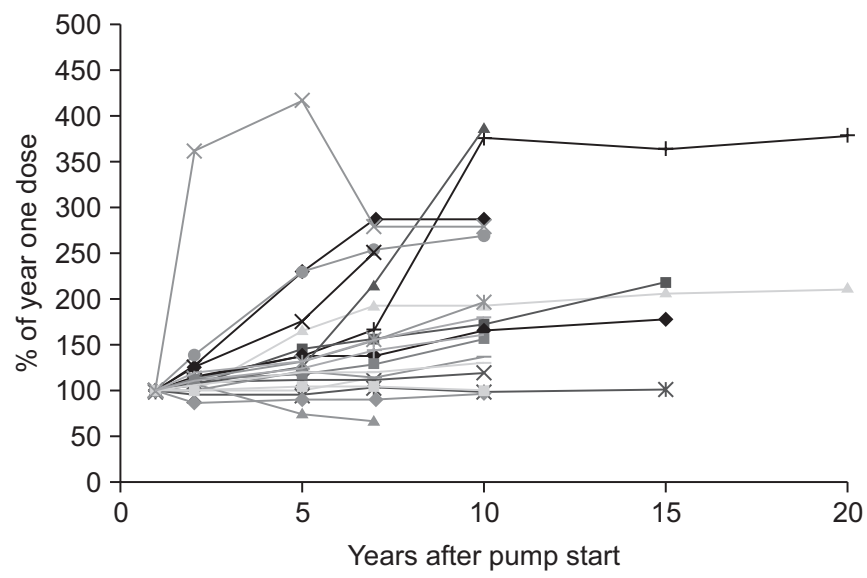

Fig. 2. Changes (\%) in long-term intrathecal baclofen dosage of patients with spinal cord injury (A) and multiple sclerosis (B). AIS, American Spinal Cord Injury Association impairment score.

groups showed a significant difference between the two groups ( 7 years, $\mathrm{p}=0.006$ and 10 years, $\mathrm{p}=0.004$ ). The $7 \mathrm{MS}$ patients with flex dose showed a mean increase to $166 \%$ (95\% CI, 146-186) after 7 years compared with 153\% (95\% CI, 116-191) in the 15 MS patients with a continuous daily dose. Both the SCI and MS groups showed low levels of spasticity after 7 and 10 years, reflected by low Ashworth scores (0-1).

A univariate analysis of the changes after 7 years included factors such as gender, patient type (SCI/MS), flex dose and pump change before year 7 , and the covariate age at pump initiation. We found that patient type was the only significant factor $(\mathrm{p}=0.048)$.

\section{DISCUSSION}

The results indicate that the demand for intrathecal baclofen from 1 year after pump start was constant in patients with SCI while increasing in progressive MS disease. At the follow-up after 7 to 10 years, the dosages in MS patients approached those found in the SCI patients. The dose of intrathecal baclofen required for an optimal effect in leg spasticity varied considerably between patients in both the SCI and MS groups, although the mean 


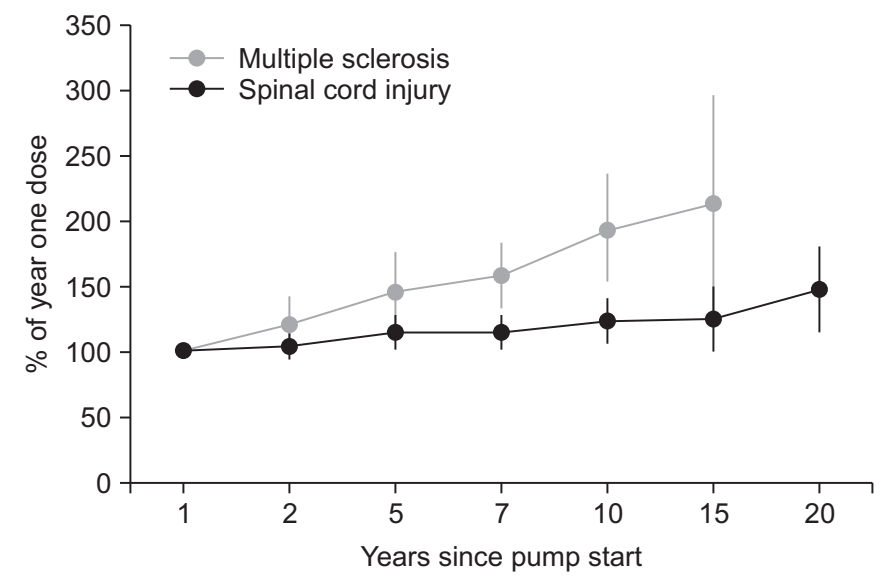

Fig. 3. Comparison of mean intrathecal baclofen dosages between patients with spinal cord injury and multiple sclerosis. The bars indicate $95 \%$ confidence interval.

dosage 1 year after pump start was considerably higher in the SCI patients in accordance with previous studies [10]. The dosage in the SCI patients appeared not to increase significantly at least up to 10 years after implantation assuming that the pump system did not malfunction. By contrast, the MS patients needed successively higher dosages despite increased trunk weakness in a few MS patients preventing an increase in dosage. A similar difference between MS and non-MS patients was found in a 2- to 3-year follow-up [16]. In the present study, the increase of EDSS score reflected the progressive nature of the disease in MS patients. A Norwegian study reported unchanged dosage after 10 years, however, the four patients showed no increase in their EDSS score [12]. Constant dosages were also found in a study followup over 4 to 8 years [17] among progressive and nonprogressive patients, although the changes in EDSS were not reported. In another study with a longer follow-up, no differences were found between MS and SCI patients [15]. In the latter study, all the dosages were included (including patients followed over a shorter time period), and the trend for long-term dosage changes was calculated using a mixed linear effect method. In that study, 30 patients were treated with a pump for 10 years, however, the number of MS and SCI patients was not indicated. Further, the study failed to mention the EDSS of patients who were followed for 7 or 10 years. It is therefore, difficult to appraise the results in that study. The univariate analysis in the present study showed that flex dose or a pump change did not significantly affect the 7 -year dos- age change. We believe that the increased baclofen dosage in the present study reflects the progressive course of disease in MS and the continuing deterioration of the descending pathways.

A major limitation of the present study relates to the perceived spasticity by the patients or their caregivers, and failed to include a systematic evaluation of the effects of spasticity on major daily activities. The perceived spasticity is strongly dependent on the mental status of the patients [18]. The mental status is commonly altered in MS. The increased dosages detected in the MS patients could also be attributed to pump system malfunction, however, such a systemic failure should also have affected SCI patients. Because of the constant baclofen dosage in SCI patients, a large dosage increase in this patient group should warrant an investigation into a possible pump failure, spasticity trigger factors or progressive spinal disease.

\section{CONFLICT OF INTEREST}

No potential conflict of interest relevant to this article was reported.

\section{ACKNOWLEDGMENTS}

This study was supported by Lars Sullivan Foundation. We acknowledge neurosurgeons (Lars-Erik Augustinsson, Björn Meyersson, Olle Corneliusson, Göran Lind, Per Almqvist, Gaston Schechtmann), neurologists (Oluf Andersen, Lars Hylliemark, Pall Ingvarsson, Katarzyna Trok), and pump refill nurses (Berit Holmqvist, Silvia Rocha, Monica Ivarsson).

\section{AUTHOR CONTRIBUTIONS}

Conceptualization: Skoog B. Data acquisition: Skoog B, Hedman B. Formal analysis: Skoog B. Funding: Skoog B. Supervision: Skoog B. Writing-original draft: Skoog B. Writing_review \& editing: Skoog B, Hedman B.

\section{REFERENCES}

1. Lance JW. Symposium synopsis. In: Feldman RG, Young RR, Koella WP, editors. Spasticity: disordered motor control. Chicago: Year Book Medical Publish- 
ers; 1980. p. 484-94.

2. Skold C, Levi R, Seiger A. Spasticity after traumatic spinal cord injury: nature, severity, and location. Arch Phys Med Rehabil 1999;80:1548-57.

3. Lechner HE, Frotzler A, Eser P. Relationship between self- and clinically rated spasticity in spinal cord injury. Arch Phys Med Rehabil 2006;87:15-9.

4. Pandyan AD, Gregoric M, Barnes MP, Wood D, Van Wijck F, Burridge J, et al. Spasticity: clinical perceptions, neurological realities and meaningful measurement. Disabil Rehabil 2005;27:2-6.

5. Burns AS, Lanig I, Grabljevec K, New PW, Bensmail $\mathrm{D}$, Ertzgaard $\mathrm{P}$, et al. Optimizing the management of disabling spasticity following spinal cord damage: the ability network: an international initiative. Arch Phys Med Rehabil 2016;97:2222-8.

6. Maynard FM, Karunas RS, Waring WP 3rd. Epidemiology of spasticity following traumatic spinal cord injury. Arch Phys Med Rehabil 1990;71:566-9.

7. Penn RD. Intrathecal baclofen for spasticity of spinal origin: seven years of experience. J Neurosurg 1992; 77:236-40.

8. Ordia JI, Fischer E, Adamski E, Chagnon KG, Spatz EL. Continuous intrathecal baclofen infusion by a programmable pump in 131 consecutive patients with severe spasticity of spinal origin. Neuromodulation 2002;5:16-24.

9. Azouvi P, Mane M, Thiebaut JB, Denys P, Remy-Neris $\mathrm{O}$, Bussel B. Intrathecal baclofen administration for control of severe spinal spasticity: functional improvement and long-term follow-up. Arch Phys Med Rehabil 1996;77:35-9.

10. Coffey JR, Cahill D, Steers W, Park TS, Ordia J, Meythaler J, et al. Intrathecal baclofen for intractable spasticity of spinal origin: results of a long-term multicenter study. J Neurosurg 1993;78:226-32.

11. Skoog B, Runmarker B, Winblad S, Ekholm S, Andersen $\mathrm{O}$. A representative cohort of patients with nonprogressive multiple sclerosis at the age of normal life expectancy. Brain 2012;135(Pt 3):900-11.

12. Rekand T, Gronning M. Treatment of spasticity related to multiple sclerosis with intrathecal baclofen: a longterm follow-up. J Rehabil Med 2011;43:511-4.

13. Natale M, D'Oria S, Nero VV, Squillante E, Gentile M, Rotondo M. Long-term effects of intrathecal baclofen in multiple sclerosis. Clin Neurol Neurosurg 2016;143: 121-5.

14. Heetla HW, Staal MJ, Kliphuis C, van Laar T. The incidence and management of tolerance in intrathecal baclofen therapy. Spinal Cord 2009;47:751-6.

15. Draulans N, Vermeersch K, Degraeuwe B, Meurrens T, Peers K, Nuttin B, et al. Intrathecal baclofen in multiple sclerosis and spinal cord injury: complications and long-term dosage evolution. Clin Rehabil 2013; 27:1137-43.

16. Nielsen JF, Hansen HJ, Sunde N, Christensen JJ. Evidence of tolerance to baclofen in treatment of severe spasticity with intrathecal baclofen. Clin Neurol Neurosurg 2002;104:142-5.

17.Zahavi A, Geertzen JH, Middel B, Staal M, Rietman JS. Long term effect (more than five years) of intrathecal baclofen on impairment, disability, and quality of life in patients with severe spasticity of spinal origin. J Neurol Neurosurg Psychiatry 2004;75:1553-7.

18. Voerman GE, Erren-Wolters CV, Fleuren JF, Hermens HJ, Geurts AC. Perceived spasticity in chronic spinal cord injured patients: associations with psychological factors. Disabil Rehabil 2010;32:775-80. 